\title{
A REVIEW OF INTERNET ADDICTION PROBLEMS USING THE PERSPECTIVE OF ETHICAL THEORIES
}

\author{
Idlan Firdaus Hairollizam, Universiti Teknologi Malaysia, ifhairollizam@gmail.com \\ Maslin Masrom, Universiti Teknologi Malaysia, maslin.kl@utm.my \\ Nor Fazilah Mohd Hashim, Universiti Teknologi Malaysia, fazilah.kl@utm.my
}

\begin{abstract}
The problem of Internet addiction has been a major concern of the global Internet community. In today's environment, it is normal that parents are seen to 'feed' their kids as young as a year old with mobile phones rather than food at restaurants. The aim of this paper is to review the problem of Internet addiction by viewing the subject using the perspectives of ethical theories. It also discusses on the relationship between the Internet of Things (IoT) and Internet addiction. The study employed desk research methodology whereby review of Internet addiction problems based on two categories of ethical theories which are ethical relativism and ethical objectivism. Two ethical relativism and six ethical objectivism theories are used to identify the morality of Internet addiction based on a given case. It is found that from the ethical relativism theories, Internet addiction cannot be deemed right or wrong due to variations of opinion, cultures, and religions. However, from the perspective of ethical objectivism, it is found that Internet addiction is morally unacceptable. Thus, it can be concluded that ethical objectivism theories are workable for judging the morality of Internet addiction problems which are found to be morally wrong.
\end{abstract}

Keywords: Internet addiction, Cyberethics, Internet of Things (IoT), Ethical theories

\section{INTRODUCTION}

Entering the digitalisation era, the advancement of technology has allowed the continuous development of the Internet to ease up human's life. With a click on the screen of our gadgets from anywhere and anytime, we get to access new knowledge, our favourite shows or movies from all over the world or even get our and desired items right in front of our doorstep. Therefore, in 2016 itself, it is found there are over 3 billion Internet users that make up about $40 \%$ of the human population of the world. In this era, where Industrial Revolution 4.0 is flourishing, many alternatives are being developed to replace humans' activities. Although technological development helps human in terms of easing the burdens of humans, some argue that they can cause a change in human behaviour too (Witt et al., 2011). Frequent, excessive, and uncontrollable dependency on Internet technology, for example, could create a change in human's behaviour by causing a disorder called Internet Addiction.

According to The Center of Internet Addiction (2019), the term Internet addiction itself is referred to as all sorts online-related, uncontrollable behaviour that interferes with the normal state of living and the ones that can cause stress to nearby people like family and friends. The organisation claims that the disorder is also known as Internet dependency or Internet compulsivity. Kapahi et al. (2013) compare the similarity between Internet addiction with drug addiction, claiming that ones who are addicted to the Internet possess the same symptoms as those of the drug addicts. The only difference between the two is that no chemical substance has been consumed by the ones addicted to the Internet.

\section{Types and Causes of Internet Addiction}

The problem of Internet addiction can be divided into several other subtypes which may also reflect the causes of Internet addiction. These subtypes arise because of the growing advancement of technological feats. In the incoming years, it is not surprising that there might more types of Internet addiction, hence also mean an increase in the cause of Internet addiction. The Centre for Internet Addiction (2019) in the United States categorises Internet addiction into five distinct subtypes. The most common form of Internet addiction is the online sex addiction which consists of user's frequent access to pornography websites. This type of addiction involves the action of downloading, watching and even trading pornography contents via an online platform. In today's world, the term 'world without border' also allows irresponsible Internet sex addicts to be involved in sexting (sexual messaging that includes exchanging of sexual images) with international Internet users. In Malaysia, applications 


\section{Issues in Information Systems \\ Volume $X$, Issue $X$, pp. $x$-x, Year}

like WeChat is frequently misused as a social media platform that allows sexting, which could lead to blackmailing (The Star, 2018).

Besides that, the first type of Internet addiction also leads up to the second type of Internet addiction problem, which is Internet fidelity and online affairs. The initial desire to accessing pornography websites that are practised frequently would lead to the involvement of these individuals to chat-rooms or social-networking platforms. These platforms provide an opportunity for these addicts to form online relationships with strangers. The virtual relationship will be even more addictive once both parties commit virtual adultery like phone sex. In addition to that, another addiction is gaming addiction. According to Kamel (2019), games like Mobile Legends, PUBG Mobile and Pokemon Go are among the famous mobile games that have made users attached to their phone. The fact that these games can be joined by an individuals' close friends or even siblings may create the 'gaming' circle that would encourage them to play more excessively. Together with improved graphics features and realistic characters, these game developers attract its subscribers to be 'happy' playing their games.

Moreover, Internet addiction can also be viewed from the perspective of compulsive shopping. Online shopping platform sometimes applies a price discrimination strategy and trick their customer using deals like Free Delivery Charge or Free Gifts deals. Other than that, information overload that is associated with the wealth of data also causes Internet users to spend an excessive amount of time in searching and collecting data (The Centre for Internet Addiction, 2019). Besides the types and causes listed above, sometimes Internet users chose to access the Internet more than they intended too as they would want to seek for peace and escape from their reality (Anderson \& Rainie, 2018). Internet users who have problems in their real-life like a financial or relationship or even family problems would choose the Internet as a medium to escape. Be it indulging themselves into excessive entertainment like watching movies or streaming their famous K-Pop artists' music videos; they mistakenly think that their action provides more comfort.

\section{Internet Addiction, Cyberethics and Ethical Theories}

Cyberethics is defined as a philosophical study of computer-related ethics that covers not only consumers' or users' behaviour but also what computers are designed to do as well as how computers affect individuals and communities. Since Internet addiction deals with the excessive usage of the Internet, or in other words a misuse of the cybertechnology, it is, therefore, part of cyberethics issues. In a study that observes the relationship between cyberethics and the users' attitude, it is found that both intellectual property and accuracy issues in cyberethics have a significant positive correlation (Masrom et al., 2013). Besides the previous study that covers the problem on primary school students, another study done by Sulaiman et al. (2018) relates the problem of Internet addiction with cyberethics issues among secondary school students in Malaysia. This study supports the findings of Masrom et al. but adds that Internet addiction also affects the accessibility issue of cyberethics. Both studies recommend that schools should respond to this rising problem by coming with awareness initiatives among students.

In judging the problems of Internet addiction which is a part of cyberethics' issue, ethical theories are considered to allow classification of different cases and situations of Internet addiction to be done. According to Quinn (2017), ethical theories allow its supporters or believers to analyse moral problems, draw conclusions and can defend the findings made when faced with the audience. In this paper, there are a few ethical theories that will be discussed, and all these theories can be categorised into two distinct groups which are ethical objectivism and ethical relativism. Ethical objectivism includes theory like the divine command theory, virtue ethics theory, Kantianism, utilitarianism, and social contract theory. The governing principle of ethical objectivism theories is that there exist moral principles that are universal and therefore true and applicable for all people. The principle of ethical objectivism theories is based on the proposition that morality lays outside the human mind, which contradicts with the idea of ethical relativism that suggested morality has no universal principles (Quinn, 2017).

\section{Internet Addiction and Internet of Things}

The Internet of Things (IoT) is defined by Gillis et al. (2020) as a system that assigns unique identifiers (UIDs) to 'things' which includes humans, animals, objects, machines both mechanical and digital or any computing devices which are all provided with unique identifiers (UIDs). Soon after assigning these 'things' with the UIDs, data will then be allowed to be transferred over an available network without the need for human-to-human interaction or human-to-computer interaction. The implementation of IoT has now been widely used not just in computers but on smartphones too. Gillis et al. (2020) through his studies, claimed that IoT allows humans to live comfortably as day to day work activities can be automated due to Internet connectivity. In the study of Perera et al. (2015), 


\section{Issues in Information Systems \\ Volume $X$, Issue $X$, pp. $x$-x, Year}

the IoT applications can be categorised into consumer, commercial, industrial and infrastructure spaces. In homes today, the IoT can be seen from the use of smart homes application like Apple Home Kit or Lenovo Smart Home Essentials. Other standalone devices like Google Home and Apple HomePod is the further enhancement of the smart home application that can be used by customers today to control things which are manually controlled before. Lights and fans can be switched on without moving, outside weather can be known without searching the Internet, and teas and coffees can be even made with machines.

However, several researchers also mentioned about the problems of IoT in the aspect of Cyberethics, including Internet addiction. According to Verbeek (2011), the influence of technology in IoT is an active agent that stirs human's moral decision making which could also change the humans itself, their privacy as well as their autonomy. Crump and Harwood (2014) in their study, supports the previous statement as he highlighted the concern pointed out by The American Civil Liberties Union (ACLU) that claims the IoT has the ability to destroy human's control over their lives. With the privacy and security matter put at risk, the IoT would enable Internet addicts in the form of hackers and other kinds of cybercriminals to perform their immoral job continuously. The urge to manipulating the data offered through the accessibility of IoT, therefore, would increase Internet addiction among the relevant group of people or organisations. There is a possibility too that with the continuous development of the Internet, the IoT might create a new form of Internet addiction; probably a new kind of pornography website that offers content through spy cams that shows live actions of the pornography victims. Therefore, the relationship between IoT and Internet addiction exists.

The addiction related to IoT gadgets, appliances or applications can be grouped in the same category as the addiction of Internet users using computers and browser, when the two subjects are put under the scope of 'technology addiction'. Technology addiction is defined by Cook (2019) as the 'inability to control one's technology use due to a dependence developed through emotional, psychological, social, environmental and biological factors.' In the article, he classifies Internet addiction to fall under the umbrella of technology addiction. The technology addiction here can be associated with the dependence of users on IoT devices to perform activities, as mentioned in the previous paragraph. Generally, in this article, the matter of IoT addiction is seen as problems that could arise concurrently with the addictions caused by the usage of Internet and browsers since these two types of addiction belong to the similar and bigger kind of addiction which is technology addiction.

\section{RESEARCH METHODOLOGY}

In this review paper, the case of Internet Addiction will be focusing on the population of Malaysians' Internet users. According to an article published by the New Straits Times on Dec 16, 2017, Malaysia has over 24 million internet users (Bernama, 2017). Out of those 24 million users, 80 per cent of them spent a minimal amount of 4 hours on social media. With the recent rise of Covid-19 pandemic issue, stages upon stages of Restricted Movement Order (RMO) or Movement Control Order (MCO), has forced many people to stay at home. With the probability that the situation might cause Internet addiction to rise, this paper is written to analyse the situation even further and hopefully could be used to prevent the spread of Internet addiction among Malaysians.

With the hypothesis that Internet addiction problems are morally wrong, the goal of this research is to review the suitable ethical theories that can be used to assess the Internet addiction problems morally. In addition to that, to thoroughly analyse the matter of Internet addiction, the paper's breadth and depth are extended by discussing on the existing literature regarding Internet addiction in Malaysia, its' effects, as well as ways to combat Internet addiction. The research is done by reviewing existing journals and literature using electronic databases which are Scopus and ScienceDirect. Besides that, open and public resources found on Google Scholar was also analysed and used. The main keywords used for finding resources are 'Internet addiction', 'ethical theories', 'Cyberethics issues' and 'Internet of Things'. Further search into the mentioned keywords such as 'online gaming', 'pornography addiction', 'ethical objectivism', and 'ethical relativism' is also used to analyse the research topic more deeply and thoroughly.

After the literature review is done, the focus is on the justification of Internet addiction problems from the perspectives of different ethical theories. In this paper, the ethical arguments are divided into two major categories, one being ethical relativism theories and another one being ethical objectivism theories. Ethical relativism theories are then further broken down into subjective relativism and cultural relativism. Ethical objectivism theories, on the other hand, are broken down into Divine Command theory, Kantianism, Act and Rule Utilitarianism, Social Contract theory and Virtue Ethics theory. For all the mentioned sub-theories, real-life cases or situations associated with Internet addiction are then discussed based on their underlying framework or principles. By using 


\section{Issues in Information Systems \\ Volume $X$, Issue $X$, pp. $x$-x, Year}

the frameworks suggested by these theories, the process of judging the Interned addiction problems are being supported theoretically and justly. Finally, by the end of the research, the most suitable ethical theories to analyse the Internet addiction can be chosen and therefore be a guideline for readers to assess Internet addiction problems in the future.

\section{RESULTS AND DISCUSSION}

\section{Internet Addiction Cases in Malaysia}

According to the International Society of Internet Addiction Conference held in Cyberjaya, the excessive usage of Internet is increasing among Malaysian youths (Cheng, 2016). Researchers from the conference revealed that $37 \%$ of Malaysian parents feel that the usage of the Internet among their children is interfering with their obligations like home-works and school-works. Not just that, $18 \%$ believed that the social activities of their children are sacrificed with their Internet activities. In the following year, the Malaysian Communications and Multimedia Commission (MCMC) conducted a study regarding the Internet addiction of Malaysians and found out that out of 725 respondents, 89\% of them are addicted to the Internet (Bernama, 2017). Not just that, more than half of them showed an increased level of anxiety, while over $30 \%$ of these respondents suffer major depression. The study figured out that over $76 \%$ of heavy internet users come from the age range of 20-49. This shows that even young adults and adults that are supposed to know the wrongs and rights and should be able to control themselves when using the Internet - fail to do so.

Further demographic studies on Internet addicts revealed that male is more susceptible to being addicted to the Internet (Kapahi et al., 2013). From the studies participated by 203 youth participants, it is found that youth with age ranging from 18 to 25 years old that goes to college or university are more inclined to be addicted to the Internet. The findings from this research are supported by Rosliza et al. (2018) that conducted a study on Malaysian undergraduate students. It is found that out of 322 respondents, 64\% of them are either addicted or problematic Internet users. Like the study done by Kapahi et al., male students are found to be more significant in terms of being either problematic or addicted Internet users. Surprisingly, these students do not spend the most screen time on exploring new information or educational purposes but instead on social networking. There are also studies on addiction among secondary school students (Sulaiman et al., 2018) and primary school students (Masrom et al., 2013).

In October 2016, the parents of a 14-year-old boy had to drag their son to seek professional therapy for the problem of Internet addiction (Cheng, 2016). The case that happened in the bustling city of Kuala Lumpur was the talk of the community as the addiction to gaming had led the boy to stay at his home for six months long. The consequence and the adverse effect could be when his games are cut off, and the boy rebelled angrily. On a more recent note, last year, a 16-year-old girl from Kuching, Sarawak was found to commit suicide after posting a poll on her Instagram story, asking whether if she should die or not. Surprisingly, the poll received a $69 \%$ of vote supporting that she should die. Dr Nurhafizah Mohd Sukor from Universiti Sains Islam Malaysia (USIM) interpreted the action as an effect of uncontrolled usage of social media that leads to adverse psychological problems (Bernama, 2019). The dependency on social media has had created the reliance of the victim to the view and opinion of her followers. If controlled at an earlier stage, there might be a chance that the victim can talk about her problems out to her family members or professional help.

\section{Analyzing Internet Addiction from the Perspective of Ethical Theories}

According to Tavani (2012), ethics is the study of morality. Both the terms, ethics and morality come from the Latin and the Greek words that are referred to as custom, habit, behaviour, and character. The study of morality hence comprises of the analysis of moral issues like the issue of Internet addiction that can be studied from the perspective of ethics. This is as some may claim that their action that is deemed as an addiction to the Internet is wrong, while others may think is right. To analyse the issue from the ethical perspective, there needs to be a framework or a general principle and structure that can be used to guide the analysis of moral decisions. In addition to that, according to Quinn (2017), out of a number of ethical theories, theories that are based on ethical objectivism, which claims that there are universal moral principles, are workable and practical compared to those of ethical relativism, which claims that there are no universal moral principles. 


\section{Issues in Information Systems \\ Volume $X$, Issue $X$, pp. $x-x$, Year}

\section{Ethical Relativism - Subjective Relativism}

If the case of Internet addiction is viewed from the perspective of subjective relativism, no conclusions can be made as the theory define that each person can decide what is wrong and what is right for themselves (Chair, 2002). In this case, rules and laws are not workable (Quinn, 2017), and in this world where there are a lot of crimes that occur because of Internet addiction, none of the doers supposedly can be punished. This theory is, therefore, unsuitable to be used as the Internet addiction itself usually involves more than one parties and may bring negative consequence to either one or all involved.

\section{Ethical Relativism - Cultural Relativism}

Cultural relativism focuses on the guidelines created by the society to determine what is right and what is wrong (Velasquez et al., 1992). In Malaysia, the dispersal of various religions, races and ethnics is massive and vary from one place to another. Although for example, the Chinese may be found to be more susceptible to Internet addiction, it is wrong for us to assume that for the Chinese, Internet addiction is not wrong. It is also unethical for society from other races to think that the whole Chinese community is Internet addict. This is because community these days vary from one another even within their own society; they have their own beliefs. Therefore, this theory is ultimately not workable as Malaysia itself is a country of various cultures.

The two theories explained above indicates that ethical relativism is sensitive in nature as the judgment made from these underlying principles depends on individuals and their respective cultural norm. According to Dr Caleb Rasado (1988), relativism theories threaten the discipline of ethics as there is no universal framework at where the human's behaviour can be judged. Since the addiction towards Internet discusses the act of people being overly attached to the Internet, the need to judge these behaviours require universal framework ethical theories. In the following section, the ethical objectivism theories are seen to provide workable frameworks in identifying the morality of Internet addiction problems.

\section{Ethical Objectivism - Divine Command Theory}

According to this theory, actions are deemed good if they are aligned with God's will, while the action is bad if it goes against the will of God (Quinn, 2017). Although different religions have a different holy book or sacred reference, it is safe to say that generally, God wants all of humankind to practise good. The question that arises is how far the similarities of these holy scriptures are? If they are different, should the different guidelines apply differently according to their followers? What if an individual is an atheist or not a practising fellow of their religion? These questions arise even in Malaysia, as there are multi-religions. In addition to that, many moral issues are not directly expressed in the scriptures, and therefore judgement is made based on analogy (McKay \& Whitehouse, 2015). Although in Malaysia, there is Syariah Law for the Muslims, the law has been adapted and adjusted to the context of today. The theory is, therefore, not applicable to judge the problem of Internet addiction.

\section{Ethical Objectivism - Kantianism}

Developed by Kant, he believed that the principle of morality must be based on reason. Ones must be able to explain whether they are doing the right or wrong thing with a supporting reason. The theory stated that what an individual wants to do is less important, but the individual needs to know what they ought to do. Individuals should be able to identify their dutifulness to act in a way that is based on the appropriate moral rule (Johnson et al., 2019) Kant separates the categorical imperative of this theory into two formulations.

According to the first formulation, Internet users should act based on moral rules that they can imagine everyone else is following. Let us say that a person spends too much time on social media. They might say that they spend their time on social media to escape from their lousy reality since they get less attention. However, if the situation is universalised, imagine everyone who has a horrible reality and needs attention going to social media for most of their time. If that is the case, since everyone is spending their time on social media, no social interactions would occur, and everybody would get less attention from each other. The individual, in return, would not get the attention they desire. As a result, that person should whatever he or she is doing is wrong.

Referring to the second formulation of Kantianism categorical imperative, ones should not use other people to get something (Fieser, 2017). In simpler words, ones cannot 'use' another person. If the case of sex addiction to Internet addicts is referred to, ones usually use another person to satisfy their sexual desire. They may either 


\section{Issues in Information Systems \\ Volume $X$, Issue $X$, pp. $x$-x, Year}

blackmail the other person by wanting to spread their pictures for not giving what they request or may also spread the explicit images and videos of others for trade or business. According to theory, one must treat others as moral equals and to the same standard. Since the described actions contradict to the moral principles of the theory, Internet addiction in this form is therefore morally unethical.

\section{Ethical Objectivism - Act Utilitarianism}

According to the principle of utilitarianism, or also called the Greatest Happiness Principle as elaborated by Quinn (2017), an action is categorised as right if it increases the total happiness of the affected parties. In contrast, an action is wrong if it decreases the total happiness of the involved parties. The theory also focuses on the consequences of an action rather than the reason for an action.

The first type of Utilitarianism is Act Utilitarianism that claims action is good if its net effect is to produce more happiness than unhappiness. In the case of Internet addiction, ones who spend an excessive amount of time of pornographic online content may think it is a good action as it satisfies their sexual desire. However, on the other hand, if analysed from the perspective of its negative consequence, ones can be affected detrimentally in terms of their health, both physical and mental health. If the positive consequence being the sexual desire satisfaction is weighed on a weighing scale with the two negative consequences being the physical health and mental health, the net effect would be that there is a more negative consequence. In this case, if ones are affected by many health problems, they would be unhappy. According to Quinn (2017), the theory is also accompanied by seven attributes to weigh further how pleasure or pain decreases or increases. They are as follows:

1) Intensity - How satisfied are Internet porn addicts? Very satisfied or reasonably satisfied?

2) Duration - How long does the satisfaction last? Usually only temporary satisfaction hence temporary pleasure. But, on the other, the health consequence could be permanent.

3) Certainty - Are they sure they will be satisfied? Are they sure they would not get any health problems?

4) Propinquity - How close are they with the other participants? Are their source of pleasures close to them in reality?

5) Fecundity - Can the pleasure they feel be produced by other means?

6) Purity - How pleasured are they? Is it $100 \%$ or less than that?

7) Extent - How many people are involved? Do they need more people to be involved to feel the pleasure? Who will be affected if they face any health issues?

Besides the example shown above, Internet addiction which gives more harm than benefit, would increase more pain than pleasure, hence more unhappiness than happiness. Lack of human interaction, anxiety, depression, waste of time on beneficial things, affected relationships, and many more effects make Internet addiction an immoral behaviour. According to this theory, if ones use the Internet for their benefits more, then it will be okay.

\section{Ethical Objectivism - Rule Utilitarianism}

Being quite similar to Kantianism, Rule Utilitarian focuses on the moral rules that would result in the greatest net increase in happiness for all affected parties rather than looking at the will motivating the action (Driver J., 2014). Unlike Act Utilitarianism that highlights the happiness indicator based on individual moral actions, the rule utilitarianism focuses on a larger group of people.

In terms of Internet addiction, collectively, as Malaysians, if everyone in the society thinks in a way that, if everyone is not addicted to the Internet, there would be more good because then there would be more social interactions and lesser anxiety and depression among Internet users; thus, it is morally right. The step in generalising the view of an action's consequence reduces bias as individuals would judge their action by asking themselves whether it is okay if everyone else does the same thing as they do. If one tends becoming addicted to gaming, the action of asking themselves whether it would be right if everyone else does the same thing would give them an answer to judge their action. The formation of legal acts in Malaysia, clearly showing the legal action that would be imposed for doing certain misconducts clearly state the rules or the moral rules of performing a specific action involving Internet addiction.

\section{Ethical Objectivism - Social Contract Theory}

According to this theory, moral problems are analysed in the view of moral rights. Everyone has their own rights to practice with the knowledge that there is a set of rules that govern the people of how to treat each other (Rachels 


\section{Issues in Information Systems \\ Volume $X$, Issue $X$, pp. $x$-x, Year}

J. \& Rachels S., 2012). The theory believes that rational people agree to accept these rules for the benefit of all, but on the condition that others follow the same rule as well. In judging the case of Internet addiction, it is quite complicated to dissect the case due to the variety of types of Internet addiction. If an online movie addict decides to stream or download any movies illegally, according to social contract theory, it is wrong to do so. This is as the action violates the legal rights of other individuals or organisations that produce the movie. In this theory, the prima facie obligation requires ones to be law-abiding as everyone is equal, and everyone wants their legal rights to be respected.

\section{Ethical Objectivism - Virtue Ethics Theory}

Last ethical theory is the Virtue Ethics theory. This theory describes an action to be right if that action would be done by a virtuous acting person (BBC, 2014). The approach is simpler compared to previous theories that require steps and steps of reasoning. In the case of Internet addicts that accesses unlawful sites or content, when being asked by anyone, they would lie and sometimes try to avoid from being asked such question. The act of dishonesty is simply against the virtue of honesty ones should be having. Hence, the action is wrong. Both the harmful action and consequence of Internet addiction would be wrong if judged by the Virtue Ethics Theory.

\section{Workable Ethical Theories}

From the ethical theories discussed, both the ethical relativism and ethical objectivism, it is found that all the ethical objectivism theories are workable except the Divine Command theory. These theories are acceptable to be used to analyse Internet addiction problems or situations since its' frameworks allow logical reasoning to be made from facts and universally held values (Quinn M., 2017). Different from the ethical relativism theories, these workable theories consider other people when deciding morally correct or immorally correct actions or behaviours. The table below shows the summary of findings for the theories discussed.

Table 1. List of workable and non-workable ethical theories for Internet addiction problems

\begin{tabular}{|l|l|}
\hline \multicolumn{1}{|c|}{ Workable Ethical Theories } & \multicolumn{1}{c|}{ Non-Workable Ethical Theories } \\
\hline 1. Kantianism & 1. Subjective Relativism \\
2. Rule Utilitarianism & 2. Cultural Relativism \\
3. Rule Utilitarianism & 3. Divine Command Theory \\
4. Social Contract Theory & \\
5. Virtue Ethics Theory & \\
\hline
\end{tabular}

As for addiction involving IoT, the techniques to assess the problem would be as like the way Internet addiction is analysed. Due to the addictions to be rooting from the same group of a bigger category of addiction called technology addiction, the technique to analyse the IoT addiction would require similar workable ethical theories.

\section{Effects of Internet Addiction}

The effects of Internet addiction increase linearly with the variation of Internet addiction types. Both mental and physical changes can occur to Internet addicts because of their uncontrollable amount of time spent on the Internet (Hoeg, 2020). When someone sits or does something excessively without taking a break, the physical change would be felt in terms of pain like backaches, neckaches or headaches. According to the author, for Internet addicts, the physical change can also be in the form of weight loss. Young kids, for example, who are trained by their parents to watch videos on YouTube in most of their daily activities, would rather not eat if they are not equipped with YouTube. This problem continues to develop at a later age until they become teenagers. Teenagers today would rather play video games with their schoolmates than to eat in the kitchen.

In addition to that, the mental health of a person could also be profoundly affected. Ones who spend so much time on social media, for example, would have low self-esteem (Young, 1988) and have an inferiority complex (Zheng, 2009) just because they compare other people's wellbeing or achievement with theirs. They tend to believe that other people's life is better than theirs, resulting in them looking down upon themselves. If not cured, these addicts would have a hard time in socialising. Without socialising, other mental health diseases like attention deficit, depression and anxiety may affect these Internet users. Other side effects of excessive Internet usage are carpal tunnel syndrome and vision problems. 


\section{Issues in Information Systems \\ Volume $X$, Issue $X$, pp. $x$-x, Year}

Besides the mentioned health problems, Internet addicts may easily get Insomnia. According to the study done by Kapahi et al. (2013), 31\% of their 203 youth questionnaire participants have trouble in sleeping. The problem of Insomnia may incite the occurrence to many other issues like feeling restless and fatigue. The failure to sleep when intended that may cause a shorter sleeping hour may cause the addicts to be tired to perform any activity the next day. This is supported by the study that found $59 \%$ of their participants to be less productive and hence perform lesser at workplace and schools. More than half of the respondents also believe that they lack concentration when doing work. Moreover, when someone gets insufficient rest or sleep, their emotions are less likely to be stable too. Hence, if in a workplace or schools, the instability of emotions would detrimentally affect the social relationship between these addicts and the surrounding people.

If explored more deeply into the different types of Internet addiction, those who are involved in online sexual content may perform masturbation excessively that can cause infertility or erectile dysfunction (Prins et al., 2002). In 2016, Harper and Hodgins through their research, claim that the number of young male adults accessing pornography through the Internet is quite significant. An excessive online shopper, on the other hand, may face financial hardships if they continue to make purchases or instalments online (Bhatia, 2019). Those involved in gaming can also face financial problems if they continue to make purchases to buy games, equipment, or accessories. Online gambling, on the other hand, can lead to bankruptcy.

\section{Ways to Combat Internet Addiction}

Internet addiction may be combatted with early intervention of its symptoms. According to The American Addiction Centre (2020), typical Internet addicts may impose emotional symptoms like always feeling guilty or inferior, anxious, depressed, isolative, defensive, being dishonest, being agitated and always avoiding work. Physical symptoms, on the other hand, are like body aches, weight gain or loss, difficulty in sleeping, carpal tunnel syndrome and blurred or strained vision. Once identified, ones can take the initiative to help their Internet addict friends by simple means like introducing their friend to people who use Internet reasonably, be a role model themselves, provide emotional support, be the talking partner to them, involve their friend with other kinds of interest that do not involve the Internet or even bringing their friend to counsellors.

According to Masrom (2013), among primary students in Malaysia, cyberethics need to be taught to them by the teachers. Awareness about the effects of Internet addiction (Sulaiman et al., 2018) and awareness about the responsible use of Internet (Rosliza et al., 2018) needs to be transmitted to both secondary school students and undergraduate students, respectively, too. Parents can also take the responsibility of educating their children well from their infancy age up to being teenagers about the controlled usage of the Internet. They can set up rules for their children.

If the symptoms have been detected, and there is nothing that can be done to curb the addiction, then clinical treatment should be sought (Przepiorka, 2014). In Malaysia, treatments of Internet addiction include self-help groups, family counselling and educational workshops. Just like those who suffer eating disorder must reteach themselves healthy eating patterns, the Internet addicts also need to relearn how to use Internet moderately. The teaching method is done by professionals using cognitive-behavioural techniques (Young, 2013). However, if the addiction gets out of control, the medication should be consumed. Antidepressants or drugs like anti-anxiety drug and Escitalopram are usually used and shown to be effective (Dell’Osso et al., 2008). There are also private organisations that offer residential rehab to Internet addicts which provide a free-from-Internet environment and is accompanied by counselling sessions.

The involvement of government bodies can include awareness and campaigns to be part of their preventive measure. Rules and laws, however, can hardly be implemented as the freedom of accessibility is part of individual rights. Laws, however, can be put in place, if addiction of Internet has led an individual to an extreme extent like involving other person's safety like online prostitution scandals or blackmailing or threatening other people to give their sexual pictures. In Malaysia, the Personal Data Protection Act 2010, for example, prevents the personal data of an individual to be abused. Scam addicts may be charged with this act if they ever try to scam or hack other Internet users' data. The Communications and Multimedia Act 1998 (Act 588) under section 211, on the other hand, prohibits individuals or organisations from using inappropriate content that or obscene, fake, threatening, or ugly in their content application services. This is an act that is used to eradicate obscene content display in social media including pornography, cyber-harassment, and bullying. If caught, one can be charged a fine up to RM50,000 or imprisonment of one year or both. In 2018, the Deputy Health Minister of Malaysia, Dr Lee Boon Chye proposed to apply Internet usage limit for those 17 years and below from 12 am to 6 am. The effort was suggested to curb the problem of excessive online gaming involvements among youths. 


\section{Issues in Information Systems \\ Volume $X$, Issue $X$, pp. $x$-x, Year}

\section{CONCLUSIONS}

In conclusion, upon dissecting into the case of Internet addiction from the view of workable ethical theories, it is learnt that despite the significant assistance provided by the Internet including the IoT, the Internet can bring a detrimental effect to its users. The review of Internet addiction problems using the ethical objectivism theories intensifies on the negative aspects of moral values rather than positive aspects. An exception is, however, given for the Divine Command theory, which although belongs to the ethical objectivism theory, is not workable to assess the Internet addiction morality value. Review of the Internet addiction problems from the eye of ethical relativism has a lack of validity. Finally, the paper also informs that the review of addiction using IoT devices can also be done using the workable ethical theories used in this paper. Therefore, everyone needs to work hand-inhand to mitigate the problem of Internet addiction, starting from parents at home, teachers and lecturers at schools and universities, the government, and most importantly each and every one of Internet users themselves. The key is moderation and good moral values.

\section{ACKNOWLEDGEMENTS}

This work has been supported by the Collaborative Research Grant (CRG) UTM National, (vote no. 08G11 and 08G61) provided by Universiti Teknologi Malaysia, Universiti Teknikal Melaka, Universiti Tenaga Nasional Malaysia, Universiti Kuala Lumpur, and Razak Faculty of Technology and Informatics.

\section{REFERENCES}

American Addiction Centers. (2020). Computer/internet addiction symptoms causes and effects. Retrieved from https://www.psychguides.com/behavioral-disorders/computer-internet-addiction/

Anderson, J., \& Rainie, L. (2018, July 3). The negatives of digital life. Available: www.pewresearch.org/internet/2018/07/03/the-negatives-of-digital-life/

Bernama. (2017, Dec 16,). Internet addiction in Malaysia at epidemic proportions: MCMC study. New Straits Times Available: www.nst.com.my/news/nation/2017/12/315031/internet-addiction-malaysia-epidemicproportions-mcmc-study

Bernama. (2019, Jun 09,). 'Internet addiction a mental disorder'. The Star Available: www.thestar.com.my/news/nation/2019/06/09/internet-addiction-a-mental-disorder

BBC. (2014). Ethics - Introduction to Virtue Ethics - BBC. Available: www.bbc.co.uk/ethics/introduction/virtue.shtml

Bhatia, V. (2019). Impact of fashion interest, materialism, and Internet addiction on e-compulsive buying behavior of apparel. Journal of Global Fashion Marketing, 10(1), 66-80.

Birruntha, S. (2019). Mobile games frenzy in Malaysia. Available: www. themalaysianreserve.com/2019/08/20/mobile-games-frenzy-in-malaysia/

Crump, C., \& Harwood, M. (2014). The net closes around us.

Available: www.tomdispatch.com/post/175822/tomgram\%3A_crump_and_harwood\%2C_the_net_closes _around_us/

Cheng, N. (2016, Oct 7). Internet addiction on the rise among Malaysian youths. The Star. Available www.thestar.com.my/news/nation/2016/10/07/internet-addiction-on-the-rise-among-malaysian-youthsenough-evidence-to-show-links-to-anxiety-decre/

Driver, J. (2014). The Stanford Encyclopedia of Philosophy. Metaphysics Research Lab, Stanford University.

Fieser, J. (2017, January 10). The Categorical Imperative. Available: www.utm.edu/staff/jfieser/class/300/categorical.htm 


\section{Issues in Information Systems \\ Volume $X$, Issue $X$, pp. $x$-x, Year}

Fullerton, J. (2019, May 15,). Teenage girl kills herself 'after Instagram poll' in Malaysia. The Guardian. Available: www.theguardian.com/world/2019/may/15/teenage-girl-kills-herself-after-instagram-poll-inmalaysia

Gedam, S., Ghosh, S., Modi, L., Goyal, A., \& Mansharamani, H. (2017). Study of internet addiction: Prevalence, pattern, and psychopathology among health professional undergraduates. Indian J Soc Psychiatry, 33(4), 305-311.

Gillis, A., Rosencrance, L., Shea, S. \& Wigmore, I. (2020). Internet of things (IoT). Available: www.internetofthingsagenda.techtarget.com/definition/Internet-of-Things-IoT

Harper, C., \& Hodgins, D. C. (2016). Examining correlates of problematic internet pornography use among university students. Journal of Behavioral Addictions, 5(2), 179-191.

Highland, J. (2016). Internet addiction, a new behavioural disorder. Available: www.monsenso.com/tag/causesof-internet-addiction/

Hoeg, N. (2020, June 18). Social Media Addiction. Available: www.addictioncenter.com/drugs/internetaddiction/

Johnson, R., \& Cureton, A. (2019). The Stanford Encyclopedia of Philosophy. Metaphysics Research Lab, Stanford University.

Kamel, H. (2019, Sep 26,). Malaysians are addicted to Internet. The Malaysian Reserve. Available: www.themalaysianreserve.com/2019/09/26/malaysians-are-addicted-to-internet/

Kapahi, A., Ling, C., Ramadass, S., \& Abdullah, N. (2013). Internet addiction in Malaysia causes and effects. iBusiness. 05(02), 72-76.

Khor, S. (2018). Govt seeks to fight internet addiction by limiting teens' internet access after midnight. Retrieved from https://says.com/my/news/putrajaya-might-limit-internet-access-after-midnight-tocontrol-internet-addiction

Malaysian Communications and Multimedia Commission. (2020). Press release: Commercialisation of 5G redefines connectivity in Malaysia. Available:www.mcmc.gov.my/en/media/pressreleases/commercialisation-of-5g-redefines-connectivity-in

Masrom, M., Nik M., N. H., \& Zainon, O. (2013). Cyberethics and internet behaviour of Malaysian primary education students. Journal of Emerging Trends in Educational Research and Policy Studies (JETERAPS), 4(1), 105-111.

McKay, R., \& Whitehouse, H. (2015). Religion and morality. Psychological Bulletin, 141(2), 447-473.

Perera, C., Liu, C. H., \& Jayawardena, S. (2015). The emerging Internet of things marketplace from an industrial perspective: A Survey. In IEEE Transactions on Emerging Topics in Computing. 3(4), 585598.

Prins, J., Blanker, M. H., Bohnen, A. M., Thomas, S., \& Bosch, J. (2002). Prevalence of erectile dysfunction: a systematic review of population-based studies, Int J Import Res., 14(6), 422-432.

Przepiorka, A. M., Blachnio, A., Miziak, B., \& Czuczwar, S. J. (2014). Clinical approaches to treatment of Internet addiction. Pharmacological Reports, 66(2), 187-191.

Quinn, M. J. (2017). Ethics for the information age. $2^{\text {nd }}$ Edition, Seattle University: Pearson Education.

Rachels, J., \& Rachels, S. (2011). The Elements of Moral Philosophy (7th ed., p. 89). New York: McGraw-Hill Education. 


\section{Issues in Information Systems \\ Volume $X$, Issue $X$, pp. $x$-x, Year}

Rainie, L., \& Anderson, J. (2017). The internet of things connectivity binge: What are the implications? Available: www.pewresearch.org/internet/2017/06/06/the-internet-of-things-connectivity-binge-whatare-the-implications/

Rosliza, A. M., Ragubathi, M. N., MKA, M. Y., \& Shaharuddin, M. S. (2018). Internet Addiction among Undergraduate Students: Evidence from a Malaysian Public University. IIUM Medical Journal, 17(2), 77-84.

The Star. (2018, April 22). Elderly Malaysian man's 5 minutes of steamy WeChat "fun” turns into blackmail. Available: www.straitstimes.com/asia/se-asia/elderly-malaysian-mans-5-minutes-of-steamy-wechat-funturns-into-blackmail

Sulaiman, Elity, K., \& Tan, C. K. (2018). Internet addiction and cyber ethic issues among students from secondary school in Malaysia. International Journal of Advances in Science Engineering and Technology (IJASEAT), 6(2), 55-58.

Tavani, H. T. (2012). Ethics and technology: Controversies, questions, and strategies for ethical computing. Fourth Edition. Rivier University: John Wiley \& Sons.

The Center for Internet Addiction Recovery. (2019a). FAQs. Available: www.netaddiction.com/faqs/

The Center for Internet Addiction Recovery. (2019b). Screen addiction. Available:

www. netaddiction.com/new/compulsive-surfing/

The Malaysian administrative modernisation and management planning unit. (2019). Personal data protection. Available: www.malaysia.gov.my/portal/content/654

Tran, B. X., Huong, L. T., Hinh, N. D., Nguyen, L. H., Le, B. N., Nong, V. M., Ho, R. C. M. (2017). A study on the influence of internet addiction and online interpersonal influences on health-related quality of life in young Vietnamese. BMC Public Health, 17(1), 138.

Witt, E. A., Massman, A. J., \& Jackson, L. A. (2011). Trends in youth’s videogame playing, overall computer use, and communication technology use: The impact of self-esteem and the big five personality factors. Computers in Human Behavior, 27(2), 763-769

Verbeek, P. (2011). Moralizing technology: Understanding and designing the morality of things. Chicago/London: University of Chicago Press.

Young, K. S. (2013). Treatment outcomes using CBT-IA with Internet-addicted patients. Journal of Behavioral Addictions, 2(4), 209-215.

Young, K. S., \& Rogers, R. C. (1998). The relationship between depression and Internet addiction. CyberPsychology \& Behavior,1(1), 25-28.

Zheng, R. (2009). Adolescent Online Social Communication and Behavior: Relationship Formation on the Internet: Relationship Formation on the Internet. Hershey, PA: Information Science Reference/IGI Global Publishing. 